\title{
The Study of the Impact of Internet on Supply Chain Finance and Its Development Trend
}

\author{
Zhaoyang $\mathrm{Wu}^{1, \mathrm{a}}$ \\ ${ }^{1}$ Shanghai GongLian Information and Technology Co, Ltd, Shanghai, P.R.C. 201203 \\ Lyceum-Northwestern University \\ awilliams1203@foxmail.com
}

\begin{abstract}
Keywords: The internet; Supply chain finance; Key enterprise; Information; Value creation
\end{abstract}
\begin{abstract}
Looking at the history of the development of supply chain finance, we can find that the information plays a more and more important role of the operation of supply chain finance, the function of its value creation more and more prominent, and the combination of supply chain finance and real industry getting more and more close. The deep integration of the Internet and supply chain finance has made supply chain finance develop into a huge network platform system with diversified entities closely integrated with the real industry. This not only breaks the necessity for the financing enterprises to provide pledges or to have real transactions with the core enterprises, but also increased the efficiency of the use of various resources, including funds, giving birth to a great deal of opportunities for interaction and value creation. The Internet has not only changed the elements and information flow of supply chain finance, but also profoundly changed its network structure and process management. Driven by cost-cutting motivation, supply chain finance, combined with emerging information technologies such as big data and cloud computing, makes the finance more networking, trade more standardizing and trading platform more specialized and vertical.
\end{abstract}

Supply chain finance is a comprehensive financial activity that relies on the entire industry supply chain and targets at the individual participants in the supply chain. . Compared with the traditional "peer-to-peer" credit model for a single enterprise, supply chain finance effectively achieves the "four-in-one" of capital flow, logistics, business flow and information flow in the whole industry supply chain, which has the features of integrity, scalability, security, stability and value-added. In recent years, supply chain finance and the Internet have become more and more closely integrated, so the structure and shape of supply chain finance have undergone tremendous changes. This thesis makes judgment on the development trend of supply chain finance on the basis of discussing the mechanism of Internet influencing supply chain finance.

\section{Evolution of Supply Chain Finance}

The first stage of the development of supply chain finance is called supply chain finance 1.0 stage, during which the commercial bank is the provider of chain financial services. Using the professional advantages in the management of supply chain financial flows, commercial banks provide a portfolio financing service that pays for the sale of goods as a basis for risk control through the binding of the responsibility of the core business with strength and the effective control of the capital flow and logistics in the supply chain to meet the needs of small-and-medium-sized enterprises(SMEs) in the supply chain. The real value of supply chain finance 1.0 lies in that commercial banks no longer require SMEs to use fixed assets for mortgages when lending to them. Instead, they are pledged by liquid assets such as accounts receivable or inventory. However, there must be a real deal between financing enterprises and core enterprises, and the credit should be increased by the core business.

Because of not participating in the operation of the supply chain, it is difficult for the commercial banks to fully grasp the logistics and information flow in the supply chain and therefore can not really play the role of an integrated risk manager. With the supply of supply chain financial services 
gradually shifting from commercial banks to its participants, supply chain finance entered the second phase of its development, which is called supply chain finance 2.0 stage. All the financial institutions in the supply chain except the manufacturing enterprises, logistics companies and commercial banks can be the financial services provider, which is called "key enterprise". In order to fully grasp the supply chain participants, especially the financing of the enterprise, the key enterprises must conduct a comprehensive management of the various processes of the supply chain. The key enterprise is the real service provider and risk taker after the supply chain finance develops into the 2.0 stage, while the commercial bank turns into the supplier with liquidity. At the 2.0 stage of supply chain finance, the key enterprise can accurately grasp the financing needs of SMEs, and reduce the credit risk through the process management for the supply chain finance. Compared with supply chain finance 1.0, the providers of supply chain finance 2.0 further reduced the demand for pledges to SMEs with financing needs, but the loan issuance still takes the real transactions of financing enterprises as the premise.

Since 2014, the combination of Internet and supply chain finance has greatly expanded the connotation of supply chain finance. The development of supply chain finance has entered the third stage --- the stage of Internet supply chain finance, at which, the provider of supply chain financial services is still the key enterprise. The Internet supply chain finance can be seen as an ecosystem whose boundary can be theoretically unlimited expanded relying on Internet technology. By using Internet technology, the key enterprise can not only reduce the adverse selection and moral hazard caused by the information asymmetry, but also greatly reduce the transaction costs caused by the information acquisition and processing. The financial needs of enterprises in the supply chain, especially financing needs, can be batch-processed under the support of Internet technologies. The application of big data technology can realize the real-time assessment of financing risk based on the multi-dimensional dynamic measurement of the operating conditions and credit conditions of all participating parties in the supply chain. Therefore, compared with the first two stages of the development of supply chain finance, Internet supply chain finance not only broke the requirements for the pledges, but also the restrictions of the real transactions that the financing enterprises had to make. Key enterprises can provide financing companies tailored financing services and personalized financing products through the mastery of the data.

\section{The Impact Mechanism of Internet on Supply Chain Finance}

The combination of Internet and supply chain finance has driven supply chain finance from the original factor finance to process finance, moving from a single lending to eco-finance. Before the deep integration of supply chain finance and the Internet, supply chain finance mainly achieve financial lending through the transactions in the industrial supply chain.; However, at the stage of Internet supply chain finance, supply chain finance relies mainly on the flow of financial resources among the organization driven by the business flow, logistics and information flow in the industrial supply chain and in turn promote the development of the industrial supply chain. The impact of the Internet on the supply chain finance can be analyzed from the following three aspects.

\section{The Internet Has Changed the Elements and Information Flow in Supply Chain Finance}

At the stage of supply chain finance 1.0, in order to control credit risk, commercial banks not only rely on core business credit increasing and third-party logistics supervision, but also pay great attention to the control of the pledge. The progress of supply chain finance 1.0 is reflected in breaking the restrictions on the mortgage of fixed assets, enabling SMEs to utilize the current assets such as inventories and trade receivables to obtain loans. Therefore, at the stage of supply chain finance 1.0, supply chain financial products are developed based on inventory and accounts receivable.

At the stage of supply chain finance 2.0, the key enterprises have decreased the requirements on the pledges, but have more control over the financial risks through controlling the trading structure and operating conditions in the supply chain instead. Therefore, compared with the concern of commercial banks on the tangible things, the key enterprises pay more attention to grasp the intangible information flow. 
One of the core values of the supply chain is the integration of information resources. At the stage of chain finance, the control of financial risk is more dependent on the control of information flow. However, the sources and forms of information at this stage are all highly complex. With the support of the Internet and Internet of Things, the interconnections between people, between people and things, and between things continuously provide various information flows in many ways. With the support of technologies such as big data and cloud platforms, the information flow formed a continuous and dynamic data-aided decision-making system after standardized processing.

In the Internet supply chain finance stage, SMEs with financing needs can enjoy tailor-made financing services which do not require them to trade with core enterprises. It is only based on the supplier's grasp of procurement, sales, logistics and related financial information of the financing enterprises. Therefore, the scope of the supply chain financial services has been greatly expanded.

\section{The Internet Has Changed the Network Structure of Supply Chain Finance}

In the supply chain finance stage 1.0, the network structure of supply chain finance is relatively simple. Commercial banks, as the providers of supply chain financial service, are not involved in the management and operation of the supply chain themselves. They can only rely on the credit of core enterprises in the supply chain to provide financing services to SMEs in upstream and downstream industries.

By the time of supply chain finance 2.0, the network structure of supply chain finance tends to be complex. The key enterprise, as the providers of supply chain financial service, are the direct participants in the supply chain and the designers and organizers of the transaction process, the logistics process and the capital flow process throughout the supply chain. Therefore, the key enterprises and upstream and downstream firms, logistics companies, commercial banks and all other supply chain entities are sequentially interdependent.

The integration of Internet and supply chain finance has profoundly changed the network structure of supply chain finance. Although the providers of supply chain financial products are still the key enterprises, the function and location of enterprises are no longer confined to the organizers of supply chain finance, which are also the architect of the smart supply chain platform. The relationship between the key enterprises and other subjects is not only sequentially dependent, but also circularly dependent and interdependent. Supported by the network information technology, the participants in the supply chain are no longer confined to the direct participants in the supply chain, but continue to expand to the indirect stakeholder according to the relationship with the supply chain. Due to the great expansion of the scope of the participants, every part in the supply chain has formed a complex community, and the supply chain finance has evolved into the financial ecological platform and industrial ecosystem.

\section{The Internet Has Changed the Process Management Supply Chain Finance}

At the supply chain finance stage 1.0, the commercial banks, as suppliers of supply chain financial products, pay more attention to the condition of capital flow. A self-compensating cash flow closed loop is designed to protect the direction and effectiveness of the use of funds to ensure the safety of funds. As for the operating activities of the supply chain, commercial banks are neither motivated nor competent to manage.

At the supply chain finance stage 2.0, the key enterprises in the supply chain can take advantage of their identity as designers and organizers to ensure the service efficiency and the safety of the funds through the process management of the supply chain after fully understanding the conditions and capabilities of the financing enterprises. The purpose of process management is not limited to ensuring the safety of loan funds. Through all-round management of the procurement, production and sales of the supply chain, the organization efficiency and resource utilization efficiency of the supply chain and can be improved, therefore providing more profits for the supply chain.

At the stage of Internet supply chain finance, the process management of supply chain finance becomes extremely complicated because of the expansion of the network structure of supply chain. The function of process management to ensure the safety of funds still exists, and the function of value creation becomes increasingly prominent. At the Internet supply chain finance stage, the process management is no longer limited to the coordination and interaction between the upstream 
and downstream enterprises in the same supply chain, as in the era of supply chain finance 2.0.Instead, the process management has expanded to the coordination and interaction among firms in different supply chains in the same industry, and further expands to strengthen the coordination and interaction between enterprises in different industries, which means that at the stage of Internet supply chain finance, organic integration is formed between upstream and downstream within the same industry and organic integration with other industries is realized, and the value space is greatly expanded in this huge "biosphere". Compared with the stages of supply chain finance 1.0 or 2.0 , the Internet supply chain finance greatly accelerated the flow of funds in the industrial chain, and produced many opportunities for interactive value creation through the interaction among a large number of customers in the network ecosystem.

\section{The Development Tendency Supply Chain Finance in the Internet Age}

The Internet has profoundly changed the structure and shape of supply chain finance. It will certainly continue to evolve towards creating greater value and continuously reducing transaction costs. With the advancement of Internet technology, the providers of supply chain financial services will acquire more and more complete and accurate information. Different types of the providers of supply chain financial service can continuously tap the value of supply chain through their own advantages in collecting and processing transaction data. Specifically, the development trend of supply chain finance are as follows.

\section{Financial Network}

Internet supply chain finance has shown a strong advantage in breaking down information barriers and reducing information asymmetry. Enterprises that provide Internet supply chain financial services are increasingly committed to using big data, mobile Internet and other technical means to connect information and data nodes originating from different organizations and sectors such as financial institutions, industry and commerce, taxation and customs to construct the panoramic and three-dimensional information of the proposed financing enterprises and minimize all kinds of financial risks caused by asymmetric information. In addition, each data information node will independently connect with other nodes to supplement the missing information and data by marketization and self-organization.

\section{The Standardization of Transactions}

The Internet makes the sharing of information more fluid and makes it possible to integrate business models with more stakeholders. The advent of Internet and big data processing technologies can standardize and automate part of the supply chain financial services. Many SMEs are distributed in a fragmented form on the large industrial ecological network formed by the Internet supply chain finance. If Internet supply chain finance can do well in transaction standardization, Internet supply chain finance will have outstanding advantages in reducing transaction costs. Standardization of supply chain financial transactions includes many dimensions, such as standardization of trading venues, standardization of trading interfaces, standardization of trading contracts, standardization of counterparts, standardization of transaction processes, standardization of transaction results, standardization of transaction data, etc. The standardization of transactions helps to ensure the rapid completion of transactions, improve transaction efficiency and expand the size of the transaction.

\section{The Trading Platforms are More Specialized and Vertical}

The Internet has given the supply chain finance infinite scalability, which develops it into a huge "biosphere" without boundaries theoretically. Businesses can provide financing companies with tailor-made financing services and personalized financing products through the mystery of the date. However, the demand for financial services of enterprises in different industrial chains is quite different because different industries have different industry attributes and characteristic. Taking the differences between different industries and the complexity of the industry chain itself into account, it is unrealistic for the providers of supply chain financial service to provide services to enterprises in different industries. In contrast, suppliers of supply chain financial services must take the advantages of their own data and accurately target their customers, finding one or several supply 
chains of which they have advantages and then continuously tap the value chain of supply chain finance. To achieve the goal of providing personalized supply chain financial products and services to enterprises in each vertically-divided supply chain, supply chain finance providers must have a deep grasp of industry attributes and industry characteristics and be able to make accurate judgments. To achieve the goal of providing personalized supply chain financial products and services to enterprises in each vertically-divided supply chain, the providers of supply chain finance must have a deep grasp of industry attributes and industry characteristics and be able to make accurate judgments. The future is bound to have more specialized and vertical business platform with the refinement and deepening of social division of labor, which integrate information consulting, trading, guarantee, investment and financing services and will be devoted to digging the value from intensive working in different industries.

\section{Conclusion}

There are three clues hided in the development process of supply chain finance. Firstly, information plays an increasingly important role in the operation of supply chain finance. Under the condition that suppliers of supply chain financial services grasp more and more comprehensive and accurate information, the requirements on pledges issued by financing enterprises and the financing activities of financing enterprises need to be based on real transactions are getting eased.

Secondly, the value creation of supply chain financial becomes more and more prominent. The initial function of supply chain finance is to meet the needs of cash flow of financing enterprises. With the development of supply chain finance, it gradually derives the function of improving and creating cash flow. Thirdly, the combination of supply chain finance and physical industry is getting closer and closer. With the continuous progress of information technology, the supply chain network will be expanded continuously, and the different supply chain networks will penetrate each other to form a complex one, in which the value of resources is quickly and fully tapped into places where maximum value can be created. The strong penetration of supply chain finance has driven the flow of resources and value creation in the real industry. The Internet presents opportunities as well as challenges for providers of supply chain financial services. In order to overcome this challenge, the providers need to enhance their abilities of information acquisition and processing, develop capabilities of online and offline supply chain service and expand the value chain of the supply chain through innovation, promoting the interaction between financial ecology and industrial ecology.

\section{References}

[1] X. Zhao. Industrial Financial Innovation: from Cross-Border to Unbounded.[J].Academic Exchanges,2016(6):136-141.

[2] L. Xie, C. X. Xu \& X. T. Lu. Comparative Study of Supply Chain Finance and Internet Finance[J].Friends of Accounting, 2014(35): 86-88.

[3] H, Song \& S. J. Chen. The Evolution of Supply Chain Finance and Internet Supply Chain Finance: A Theoretical Framework[J].Journal of Renmin University of China, 2016(5): 95-104.

[4] H. Song. Internet Supply Chain Finance.[M]. Beijing: China Renmin University Press, 2017. 